\title{
SOBRE LA MEDALLA A GODOY DE LA REAL SOCIEDAD ECONÓMICA DE AMIGOS DEL PAÍS DE VALENCIA ACU- ÑADA EN 1807. DOCUMENTOS INÉDITOS
}

\section{ABOUT THE MEDAL TO GODOY OF THE REAL SOCIEDAD ECONÓMICA DE AMIGOS DEL PAÍS DE VALENCIA MINTED IN 1807. UNPUBLISHED PAPERS}

\author{
Juan Antonio SENDRA IBÁÑEZ \\ Excelentísimo Ayuntamiento de Sueca, Valencia. \\ Societat Catalana d'Estudis Numismàtics
}

\begin{abstract}
Resumen: Entre los documentos del archivo de la Real Sociedad Económica de Amigos del País de Valencia (RSEAPV) ${ }^{1}$, se encuentra un conjunto muy interesante concerniente a la realización de una medalla por parte de esta sociedad en honor de Manuel Godoy, Príncipe de la Paz. Es en enero de 1807 cuando la RSEAPV decide nombrarlo miembro protector de esa Real Sociedad y, en agradecimiento a su aceptación y su reciente nombramiento al Grande Almirantazgo de España e Yndias, acuña la medalla sobre la cual presento este trabajo. El estudio detallado de los citados documentos nos permitirá ir más allá de las imágenes representadas en el reverso de la misma, proporcionándonos su correcta interpretación dentro del contexto histórico del momento.

Palabras clave: Valencia, Godoy, medalla, Neptuno, Peleguer, Real Sociedad Económica de Amigos del País.

Abstract: Among the archival documents of the Real Sociedad Económica de Amigos del País de Valencia (RSEAPV), there is a very interesting set regarding the strike of a medal by this society honouring Manuel Godoy, the so-called "Prince of the Peace". It was in January 1807 when the RSEAPV decided to appoint him supporting member of this
\end{abstract}

\footnotetext{
${ }^{1}$ Los documentos publicados en el presente trabajo pueden consultarse online desde Mayo de 2013 a través del enlace http://riunet.upv.es/handle/10251/18484, aunque las imágenes de los mismos utilizadas en este artículo fueron obtenidas durante mi visita al archivo de la Real Sociedad en febrero de 2012 por lo que carecen de marca de agua. La Real Sociedad Económica de Amigos del País de Valencia cuenta con un Archivo histórico digitalizado (fondo documental) de 8.360 documentos PDF multipágina que contemplan la historia de la entidad desde la fecha de su fundación, en 1776. Desde aquí mi agradecimiento a esta institución por las facilidades prestadas para la realización del presente trabajo. Así mismo agradecer al Sr. M. C. su amabilidad por facilitarme y permitirme reproducir la imagen de la medalla acuñada en plomo.
} 
Royal Society and, in appreciation for his acceptance and to commemorate his recent appointment to the Great Admiralty of Spain and the Indies, to strike the medal that I'm introducing with this review. The detailed study of this documentation allows us to go beyond the images depicted on the reverse of the medal and to set its significance in the historical context of its time.

Keywords: Valencia, Godoy, medal, Neptune, Peleguer, Real Sociedad Económica de Amigos del País de Valencia.

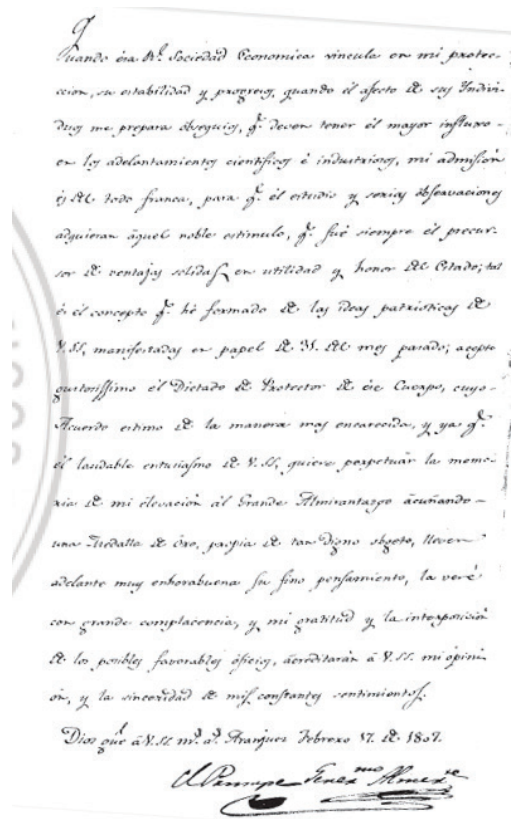

Carta de Godoy a la RSEAPV aceptando su nombramiento como Protector de la Sociedad, 17 de Febrero de 1807.

La medalla fue publicada por primera vez en el catálogo de la colección Vidal Quadras (VIDAL QUADRAS 1892: 197 n 14168), siendo estudiada y publicada posteriormente por diversos autores y catálogos, como Medallero Valenciano del Barón de San Petrillo (CARUANA 1955: 89 n n $^{\mathbf{0}}$ 119), Vives (VIVES 1916: $355 \mathrm{n}^{\mathrm{o}}$ 718), Mateu y Llopis (MATEU 1958: 324; 326), García Corredor

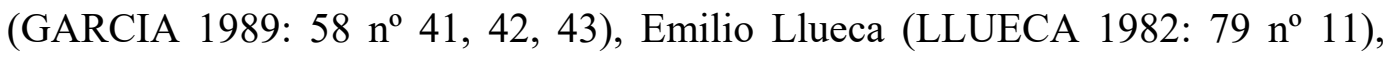
Ruiz Trapero (RUIZ ET ALII 2003: 386,387 n 314), Villena (VILLENA 2004), Cano Cuesta (CANO 2005) y Miquel Crusafont (CRUSAFONT 2006: 157, $353 \mathrm{n}^{\circ}$ 331). Hasta este momento, el estudio de esta medalla se ha circunscrito principalmente a la mera descripción de los motivos representados, información general sobre los diferentes metales en que estuvo acuñada o sobre los grabadores de la misma, salvo en el catálogo de Ruiz Trapero, en el que se destaca sobre la medalla su concepción con motivo del nombramiento de Godoy al Gran Almirantazgo. 
Los documentos ahora estudiados e inéditos se encuentran clasificados bajo el epígrafe 1807/C-48 V. Varios, no 11 y 12, y llevan como título general Sobre la Medalla del Serenísimo Señor Protector. Se trata de diversos oficios entre miembros de la sociedad, bocetos y proyectos aportados por socios, así como dos cartas manuscritas del propio Godoy remitidas a la Sociedad. El último grupo de documentos corresponde a 13 cartas de otros tantos miembros de la Sociedad, acusando el recibo de la estampa y explicación de la medalla que se les remitió y manifestando su satisfacción al respecto.

El estudio de estos documentos nos permite reconstruir cronológicamente el proceso que se siguió para el proyecto y ejecución de la medalla, obtener distintos datos desconocidos hasta el momento sobre la misma así como la confirmación de otros, y por último la descripción completa y explicación de los motivos acuñados con el sentido pretendido por sus promotores.
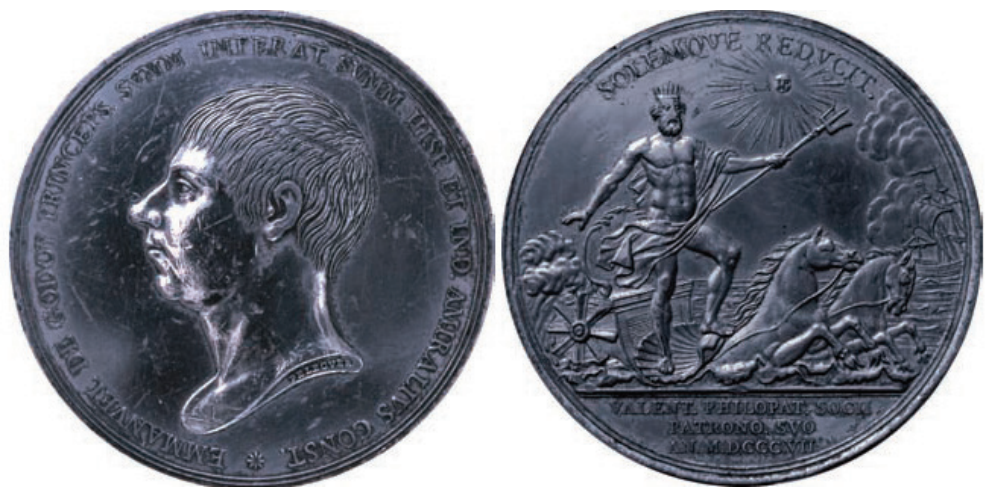

Medalla acuñada en plata por la RSEAPV en honor a Godoy, 1807. Museo Arqueológico Nacional ${ }^{2}$.

\section{GODOY Y LA REAL SOCIEDAD ECONÓMICA DE AMIGOS DEL PAÍS DE VALENCIA}

La RSEAPV fue fundada en el año 1776 por un grupo de siete patricios valencianos con la intención de fomentar y mejorar la industria popular valenciana. Sus estatutos no fueron definitivamente aprobados hasta 1785, debido a la exigencia de su adaptación a los redactados por la sociedad matritense, y por ende, quedar bajo el control del gobierno central y de Campomanes en particular, el cual quería para estas sociedades un modelo más cercano a la burguesía y alejado de la nobleza, evitando así cualquier posible disidencia.

${ }^{2}$ Tomada de Gimeno 2011. 


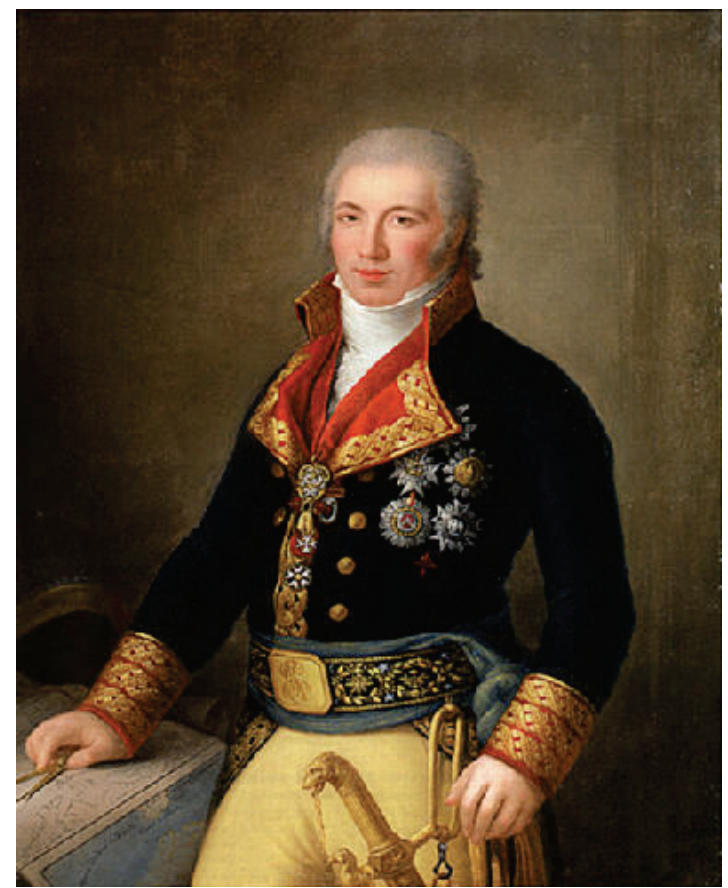

Godoy retratado por Agustín Esteve. Art Institute Chicago.

Manuel Godoy, aunque provenía de la hidalguía, tuvo una rápida ascensión política al convertirse en favorito del rey Carlos IV, otorgándole a lo largo de su carrera numerosos títulos y confiriéndole el rey a través de éstos un gran poder frente a la nobleza. Entre muchos otros cabe destacar el nombramiento de Príncipe de la Paz en el año 1795 y el de Generalísimo en 1801, título nunca otorgado antes en España. Finalmente, en 1807, cercana ya su caída, Carlos IV le concedió el título de Gran Almirante, con tratamiento de Alteza Serenísima, y de presidente del Consejo de Estado.

\section{LA MEDALLA, PROYECTOS E IDEAS}

Los primeros documentos los encontramos a finales de enero de 1807 en el que se cita la Junta ordinaria de la RSEAPV, pidiendo una idea para la medalla. El 11 de febrero, reciben contestación por parte de los señores Peyrolón, Manuel de Velasco, Joaquín de la Croix y Joaquín Fusells, miembros de la comisión encargada de la realización de la medalla, los cuales tras deliberar en diferentes ocasiones adjuntan la idea, dibujo e inscripciones. Así mismo, adjunta el proyecto presentado por Pedro Vicente Galabert. 


\subsection{El proyecto de Galabert}

El proyecto de Galabert, fechado en Vinalesa el 5 de Febrero de 1807, no fue finalmente aceptado, aunque el remitido por la comisión oficial recoge claramente su idea del anverso, cambiando algún detalle como la inscripción de la leyenda en latín y la omisión de la fecha en esta cara. En cuanto al reverso, Galabert optó por una representación de Neptuno en pie, sujetando un tridente en la mano derecha y atributos militares en la izquierda, a la orilla del mar y zarpando una nave de guerra. Neptuno con la cabeza vuelta hacia una matrona, la cual representaría a la RSEAPV, completando la escena los atributos de la sociedad, olivo y colmena, y una ciudad en la lejanía. Todo ello queriendo expresar que el Dios está contestando a la matrona "que conseguirá la paz, la riqueza y la felicidad patria, presentándose con grandes fuerzas en la mar, y en el continente". Por último justifica la adopción como símbolo de Neptuno, añadiendo que la ciudad de Trezena para indicar el comercio dirigido por la sabiduría puso en sus monedas el tridente en el reverso y la cabeza de minerva en el anverso.

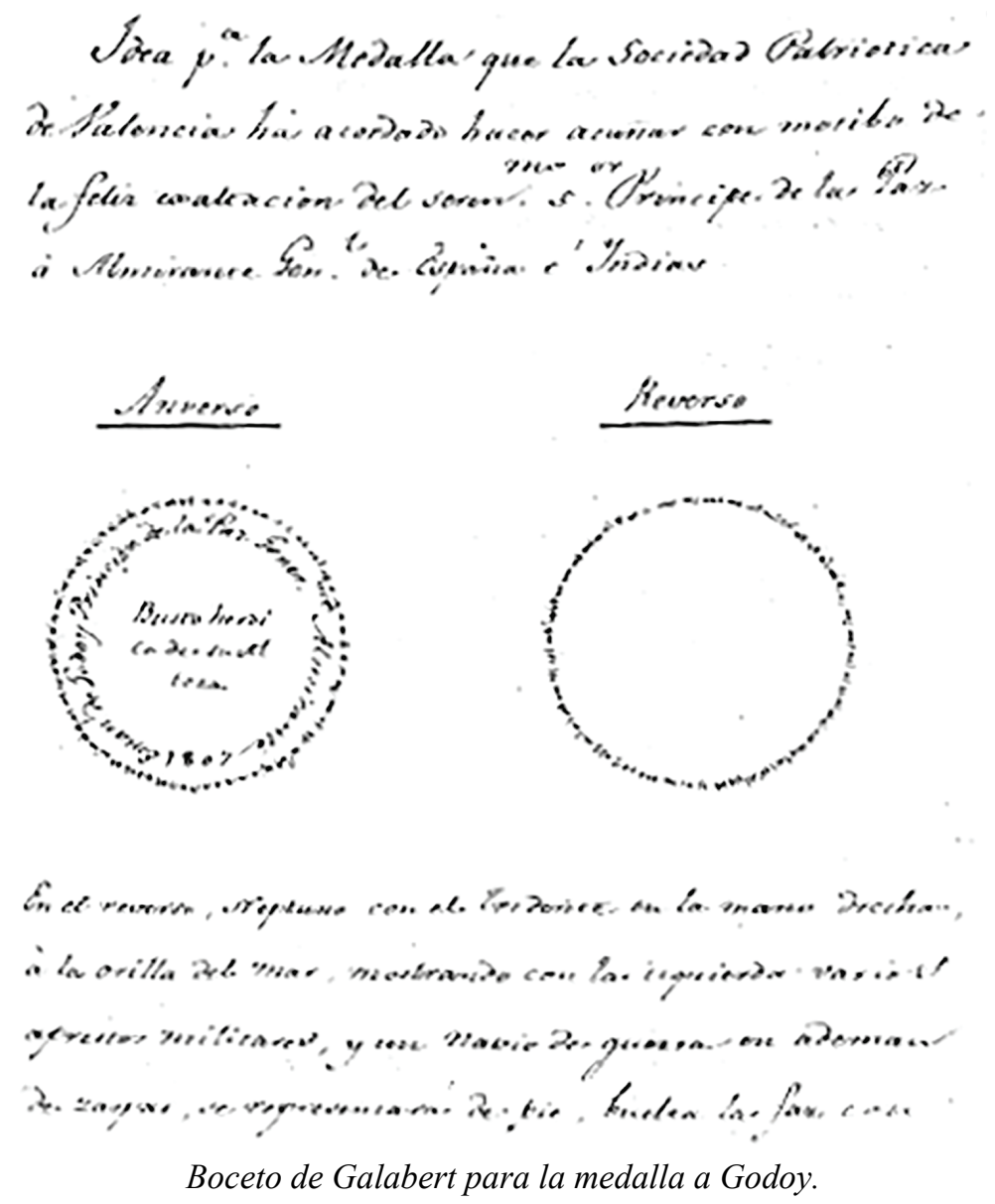




\title{
2.2. El proyecto de Fusells
}

El proyecto firmado por Fusells no lleva fecha y fue el que finalmente se llevó a cabo, aunque con alguna pequeña modificación. En su propuesta de anverso, el busto de Godoy debía aparecer al estilo romano, y leyenda con la forma ENMANUEL DE GODOY PRINCEPS. HISP. ET IND. ADMIRALIVS CONST. aunque en la medalla aparece definitivamente la leyenda ENMANUEL DE GODOY PRINCEPS. SVMM. IMPERAT. SVMM. HISP. ET IND. ADMIRALIVS CONST. (Manuel de Godoy Príncipe Generalísimo constituido Gran Almirante de España y de las Indias).

En cuanto al reverso, opta por una representación de Neptuno sobre su carro en actitud de dominar y pacificar los mares. Estos se expresarán alterados y borrascosos, lo que indicarán las olas levantadas, y alguna nave trastornada. La admosfera se advertirá cubierta de nubes, que Neptuno apartará con el tridente; y entre ellos se dexará ver el Sol. La acción de pacificar los mares podrá declararse extendiendo Neptuno la mano sobre ellos. La nave manifestará en su configuración el estilo de la edad heroyea. En la parte superior de la circunferencia se inscribirá el hemistichio de Virgilio en el libro 1 de la Eneida verso 143 y que dice asi:

\author{
Solemque reducit \\ Exergo \\ Valentini Philopatrii Soccii \\ Patrono suo \\ Anno M.DCCC.VII.
}

Tras esta descripción de su idea para la medalla, Fusells continúa con la explicación de su elección de estos motivos, asimilando los hechos narrados en el citado verso de la Eneida con las circunstancias bélicas que estaban viviendo y con sus deseos. Es en este párrafo donde encontramos el verdadero significado grabado en el reverso, al identificar sin duda a Juno con los británicos:

Después de la tempestad que para arruinar la armada Troyana excitaron en el mar Tirreno las sugestiones de Juno, en quien puede simbolizarse la altivez, el dolo, y la inhumanidad Britanica. 


\subsection{Cantidades acuñadas}

Entre los documentos analizados se encuentran algunos que nos dan una idea mínima de la cantidad de ejemplares acuñados, así como los metales en que fue acuñada la medalla.

En el primero de ellos, fechado el 20 de Mayo en Madrid y dirigido al secretario de la sociedad, el vicepresidente de la entidad el Marqués de Valera comunica a la RSEAPV la entrega al Príncipe de la Paz de una medalla de oro y doce ejemplares de plata junto con una carta solicitándole audiencia particular. En el segundo documento, fechado el día 8 de Agosto, se remite desde la sociedad una nueva misiva a Godoy en la que se dan por enterados de que ha recibido las medallas, y que con motivo de que la nación se entere del anuncio feliz que debe prometerse de este nombramiento ha resuelto que dicha medalla se grabe también en dulce.

Entre la contabilidad de la sociedad se haya algún recibo de pago a Peleguer ese mismo año por la realización de medallas, incluyendo la cantidad fabricada de las mismas, pero relativas a los premios otorgados. De la medalla de Godoy únicamente se encuentra el documento fechado el 6 de Junio de 1807 firmado por el contador Inocencio de Llanos dando por correctas las cuentas presentadas por Peleguer relativas al coste de fabricación, sin más datos.

Por tanto, conocemos la existencia de al menos un ejemplar realizado en oro, desaparecido hasta el momento, y de al menos doce ejemplares de plata. Actualmente son apenas cuatro o cinco los ejemplares conocidos en plata, y dos en plomo. En el catálogo de Caruana se indica también una variante en cobre, sin indicación de peso, así como en el de García Corredor, probablemente tomando este dato de Caruana. No he encontrado documentación respecto a esta posible acuñación en cobre, ni ningún ejemplar, por lo que este dato resta por confirmar.
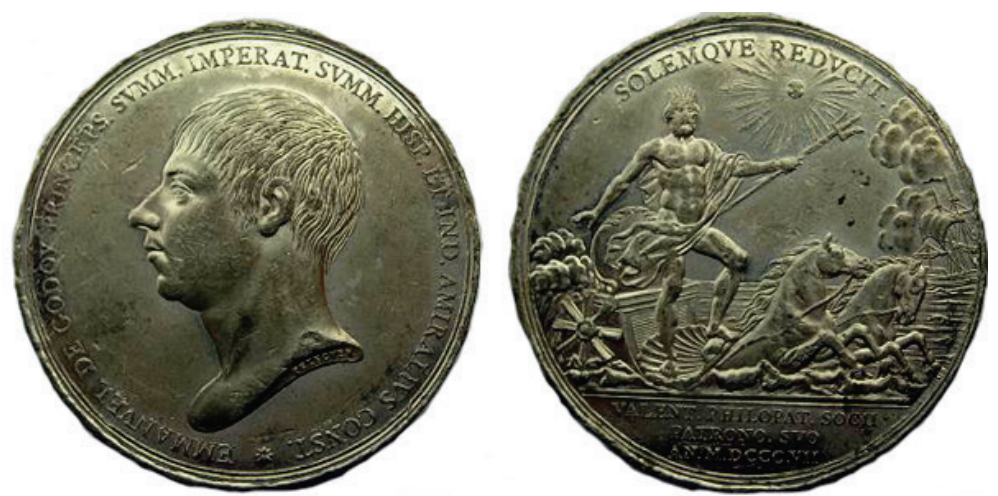

Variante en plomo plateado. Diámetro, 48mm. Peso, 76gr. Colección M.C. 


\subsection{Estampa explicativa de la medalla}

Los últimos documentos concernientes a la medalla son cartas de recibo de la explicación de la medalla por parte de algunos miembros de la sociedad. En ellas se complacen de la recepción de la estampa, manifiestan su reconocimiento oficial al obsequio y celebran la protección ofrecida por el Príncipe de la Paz. El 29 de Julio de 1807 es remitida una carta a los socios remitiéndoles un ejemplar de la estampa y explicación de la medalla, así como una copia de la carta de recibo de la medalla, su agradecimiento y ofrecimiento de protección por parte de Godoy.

En la explicación, tomada del proyecto de Fusells, desaparece la forma explícita en que éste identificaba a Juno con los británicos, apareciendo simplemente como los enemigos de la paz.

\section{ESTAMPA Y EXPLICACION de la Medalla acuñada en oro y plata por la Real Sociedad Económica de Amigos del Pais de Valencia en honór del Serenísimo Señor Príncipe de la Paz, Generalísimo de Mar y Tierra, y en memoria de su elevacion á la alta dignidad de Gran Almi- rante de Espańa é Indias.}

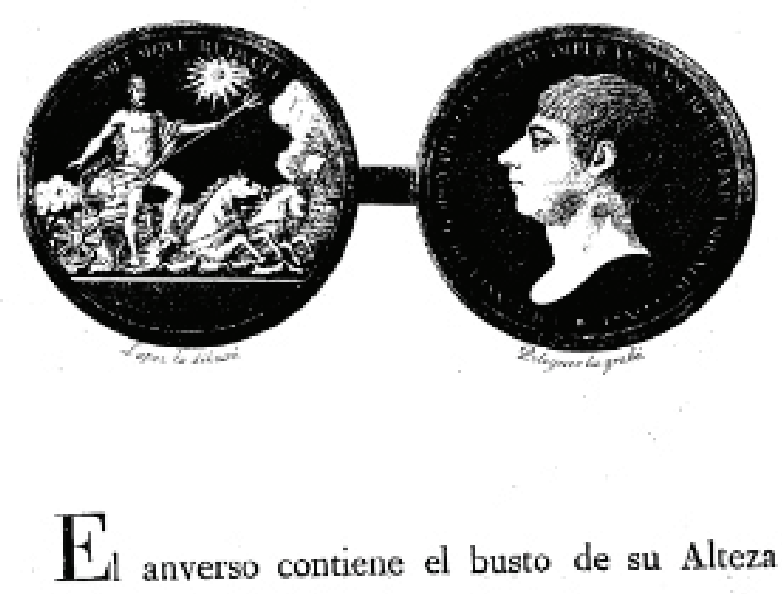




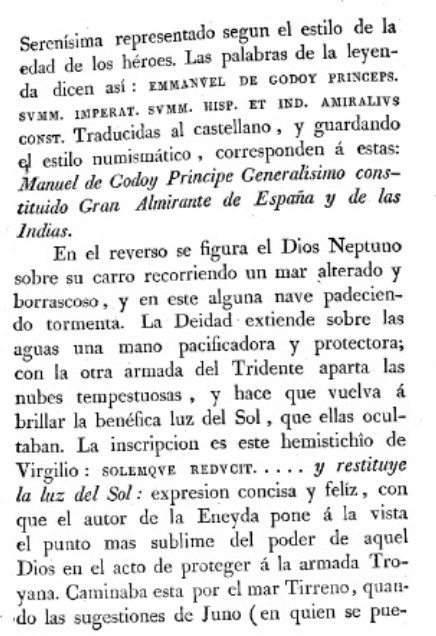

\subsection{Algunos datos del grabador Manuel Peleguer}

Aprovecharé la realización de este artículo para dar a conocer un nuevo dato biográfico del grabador Manuel Peleguer relativo a su fallecimiento. En un documento de tres páginas de este archivo (RSAPV 1831 C-32 V. VARIOS no 4), fechado en Mayo de 1831 y remitido a la sociedad por Miguel Peleguer - hijo de Manuel Peleguer- y concerniente al depósito en su casa de las dos prensas de acuñar las medallas, encontramos el dato que nos indica la fecha de su muerte, habiendo ocurrido esta según se indica en la misiva a finales de Marzo de ese mismo año 1831.
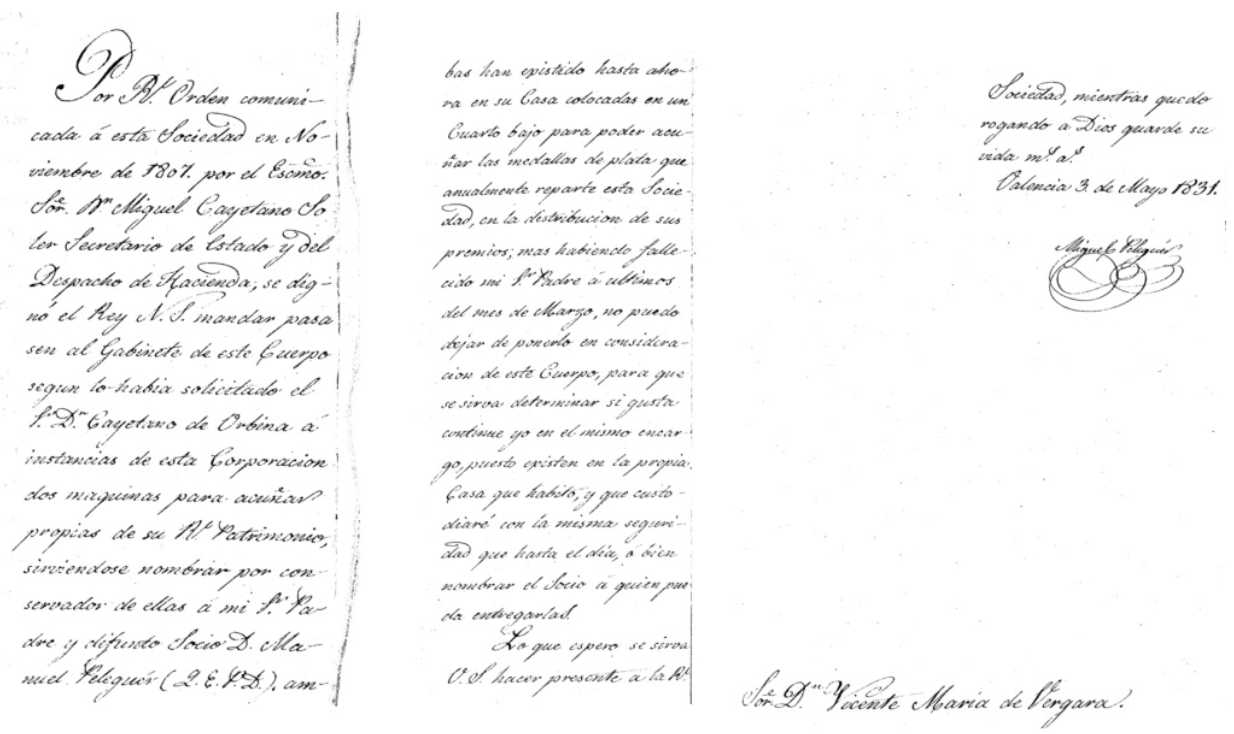


\section{CONCLUSIONES}

Los ataques a barcos españoles por parte de los británicos en el año 1804 desembocaron a finales de ese año en una declaración de guerra. Fruto de esta guerra aconteció la gran derrota de la Armada franco-española en aguas de Trafalgar en octubre de 1805. Durante el siguiente año siguieron ataques británicos al Virreinato de la Plata y Montevideo, resultando con ello "que todo el comercio en Barcelona se hallaba agobiado" y provocando despidos tanto en el sector artesano como fabril (ANES-1994:313). Es en este ambiente de guerra y bloqueo comercial en el que la RSEAPV decidió la realización de la medalla, y en el que encontramos el verdadero sentido pretendido por sus promotores con los motivos representados en ella.

A partir de la lectura tanto de los bocetos como de la estampa explicativa de la medalla, podemos interpretar correctamente la iconografía que aparece en el reverso de la medalla, el cual nos muestra a Godoy como un Dios Neptuno pacificador de las aguas turbulentas en las que la nave (el comercio) sufre los embates de la tormenta provocada por los británicos identificados con Juno. El tridente como arma, aparta las nubes tempestuosas, pudiendo asimilarse esta imagen con el deseo de que la Armada española destruya a la inglesa que tantos desastres les había causado. Con ello, Neptuno hará brillar de nuevo el sol que éstas ocultaban, significando la restitución del comercio de nuevo. Por último, la leyenda escogida de la Eneida dota a todo el conjunto de sentido, ensalzando al Príncipe de la Paz como protector y pacificador de España y Europa.

La medalla se encuadra estilísticamente dentro de la corriente neoclásica imperante en el momento, y que encaja perfectamente en el concepto y función de la medalla dado por Gimeno (GIMENO 2011): una medalla de imagen directamente asimilable, que atienda esta función divulgadora al servicio de la institución, a lo que cabría añadir la función perpetuadora de la memoria histórica del acontecimiento representado.

La RSEAPV disponía de dos importantes activos para la consecución de su objetivo: la tecnología y los artistas de primer orden al servicio de la institución. Tecnológicamente disponía de dos prensas de acuñar -sistema al alcance de pocas entidades privadas en aquel momento- lo que le permitía una calidad de detalle y acabado de la medalla muy superior al método de fabricación por fundición. En cuanto al factor artístico, la presencia del pintor Vicente López, formado en la Academia de San Carlos de Valencia y San Fernando de Madrid -y que fue pintor de cámara con Carlos IV y Fernando VII- el cual se encargó de dibujarla, y de 
Manuel Peleguer como artista reconocido en el arte del grabado. Peleguer había sido el artífice de distintas medallas desde hacía más de veinte años, siendo ya en este momento director de la Academia de San Carlos, donde se formaban los futuros grabadores.
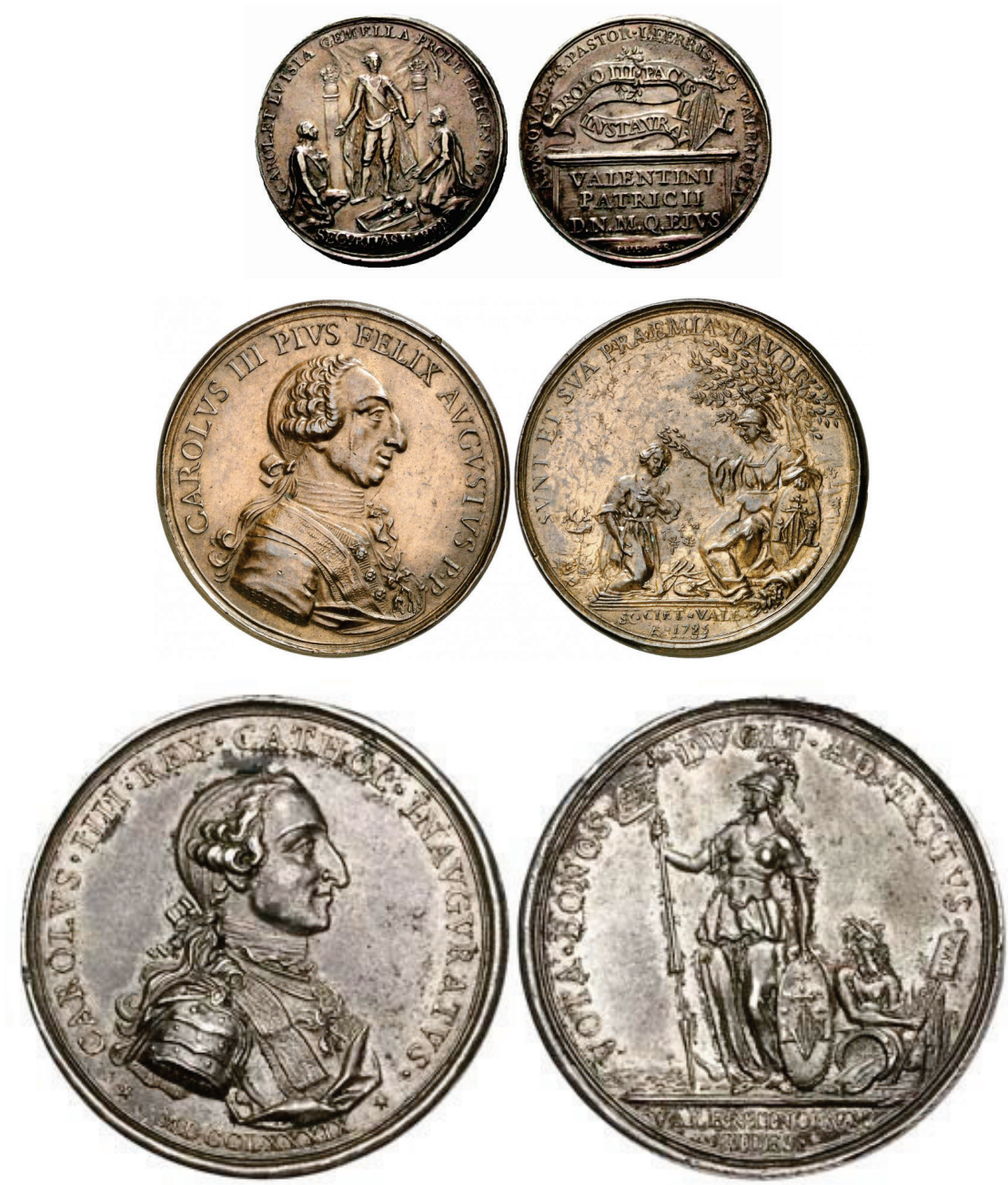

Distintos trabajos realizados por Manuel Peleguer. 1- Al natalicio de los gemelos reales, por patricios valencianos, plata, 1784. Subasta Baldwin 9-5-05 lote 33. 2- Creación de los estatutos de la RSEAPV, plata, 1785. Subasta Aureo-Calico 27-5-14 lote 3431. 3.- Proclamación en Valencia de Carlos IV, plata, 1789. Subasta Ibercoin 28-6-12 lote 862.

Con todos estos medios a su alcance, la RSEAPV pretendió la realización de una medalla de gran prestigio, como así lo atestiguan los medios utilizados técnicos y humanos- y el hecho excepcional de acuñarla en oro (cuando lo habitual era realizarlas en plata o cobre), y en donde el homenajeado pudiera verse claramente reflejado, lanzando al mismo tiempo un mensaje al enemigo (los británicos, tal como indica el boceto) que tanto estaba afectando a la industria y el 
comercio. Todo ello con la finalidad de conseguir un acercamiento máximo al Príncipe de la Paz en búsqueda de su apoyo y protección.

\section{BIBLIOGRAFIA}

Art Insitute Chicago: http://www.artic.edu/aic/collections/artwork/80579

Crusafont i Sabater, Miquel: Medalles conmemoratives dels Països Catalans $i$ de la Corona Catalano-aragonesa (S. $X V$-XX). Societat Catalana d'Estudis Numismàtics. IEC. Barcelona 2006.

Anes, Gonzalo. El siglo de las luces. Historia de España dirigida por Miguel Artola. Alizan Editorial 1994.

Cano Cuesta, Marina. Catálogo de medallas españolas. Museo Nacional del Prado. Madrid, 2005.

Caruana i Reig, Josep: Medallero Valenciano. Archivo de Arte Valenciano. Valencia 1930-1931.

García Corredor, José Luis: Mil medallas valencianas. Valencia 1989

Gimeno, Javier. "La medalla española entre los siglos XVIII y XX. Arte y artistas”. XIV Congreso Nacional de Numismática, Madrid 2011, pp. 139-166

Godoy, M. (1807). Diversas cartas sobre el nombramiento del Príncipe de la Paz como Protector de la Sociedad. Respuesta del mismo aceptando el nombramiento. Real Sociedad Económica de Amigos del País de Valencia http://hdl.handle.net/10251/20605

Godoy, M. (1807). Proyectos, ideas, estampa y explicación de una medalla acuñada en oro y plata por la Sociedad, en honor del Príncipe de la Paz por su nombramiento com Gran Almirante de España e Indias. Carta de respuesta y gratitud del Príncipe de la Paz. Real Sociedad Económica de Amigos del País de Valencia. http://hdl.handle.net/10251/20606

Godoy, M. (1807). Cartas de recibo de la explicación de la medalla acuñada en honor del Príncipe de la Paz, Protector de la Sociedad. Real Sociedad Económica de Amigos del País de Valencia. http://hdl.handle.net/10251/20607

Llueca i Ubeda, Emilio: El grabador Manuel Peleguer y su tiempo. Valencia 1982.

Mateu i Llopis, Felipe: Bibliografía de la historia monetaria de España.

Peleguer, Miguel: Miguel Peleguer desea se le confirme el encargo hecho a su difunto padre de custodiar dos máquinas para acuñar las medallas de plata que anualmente reparte la Sociedad. http://hdl.handle.net/10251/20780 
Ruiz Trapero, María. Catálogo de la colección de medallas españolas de Patrimonio Nacional. Volumen I (Carlos I-Fernando VII). Consejería de Educación de la Comunidad de Madrid. Madrid 2003.

Vidal Quadras, Manuel. Catálogo de la colección de monedas y medallas de Manuel Vidal Quadras i Ramón. Barcelona 1892.

Villena, Elvira El arte de la medalla en la España ilustrada (Del 28 de abril al 20 de junio de 2004). Centro Cultural Conde Duque, Madrid.

Vives, Antonio. Medallas de la Casa de Borbón. Madrid 1916. 